\title{
Postprandial changes in plasma growth hormone and insulin concentrations in calves before and after weaning
}

\author{
K. Katoh¹, G. Furukawa, Y. Kobayashi and Y. Obara \\ Department of Animal Physiology, Graduate School of Agricultural Science, Tohoku University \\ Amamiyamachi, Aoba-ku, Sendai 981-8555, Japan
}

\begin{abstract}
Plasma GH and insulin concentrations following feeding as well as following stimulation with GH-releasing agonists were compared between milk-fed (3-wk old) and concentrate + hay-fed (12-wk old) calves. Feeding of a milk replacer diet, but not the concentrate + hay, significantly increased plasma GH, insulin and glucose concentrations. When calves were maintained on a milk replacer diet until $12 \mathrm{wk}$ of age, postprandial plasma GH concentration was not different from that in the age-matched weaned group. It is concluded that postprandial levels in plasma GH and insulin concentrations are altered after weaning.
\end{abstract}

KEY WORDS: growth hormone, insulin, weaning, feeding, calf

\section{INTRODUCTION}

Weaning, after birth, is the most drastic event that neonates experience, because they are obliged to change from liquid milk to solid feeds. Weaning alters the digestive and metabolic functions to meet the change of the quality of diets, because weaning abolishes the expression of leptin and CCK receptors in the rumen and abomasum of calves (Yonekura et al., 2002). In addition, when calves were fed a milk replacer diet until 13 wk of age, the leptin expression in the epithelium of the rumen and abomasum (Yonekura et al., 2002), and carbonic anhydrase activity and ion secretion in the parotid gland (Kitade et al., 2002) also remained at the preweaning level. When veal calves are fed milk without solid feed, plasma glucose and insulin concentrations were greater than those of weanlings (Blum and Hammon, 1999).

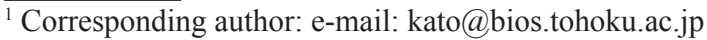


In the present study, we observed changes in the secretion of GH and insulin in response to feeding and the stimulation with GH-releasing hormone (GHRH) and peptide (GHRP-6) in milk-fed (3-wk old) and concentrate + hay-fed (12-wk old) calves. We also compared the endocrine responses to feeding between the animals maintained on a milk replacer diet until $12 \mathrm{wk}$ of age and those of weaned, agematched control in order to further understand the mechanisms.

\section{MATERIAL AND METHODS}

The animals $(n=12)$ were fed on a milk replacer diet until $4 \mathrm{wk}$ of age, on a milk replacer + a calf starter diet after $4 \mathrm{wk}$, and then on a calf starter + hay from $7 \mathrm{wk}$ to $13 \mathrm{wk}$. In the other experiment, the animals $(n=5)$ were fed only a milk replacer diet until $12 \mathrm{wk}$ of age. All calves were fed diets twice daily. At 3 wk and 12 wk of age, blood samples were collected every $15 \mathrm{~min}$ before and after either: feeding, the venous injection of hGHRH $(0.25 \mu \mathrm{g} / \mathrm{kg}$, Peptide Institute, Japan $)$ or the venous injection of GHRP-6 (2.5 $\mu \mathrm{g} / \mathrm{kg}$, Peptide Institute, Japan). Hormone concentrations were measured by radioimmunoassay (Ishiwata et al., 2000). The values are expressed as the mean. For statistical analysis, ANOVA and Student's $t$-test were employed.

\section{RESULTS}

Feeding of a milk replacer diet in the 3-wk old group significantly increased from 13.0 to $45.3 \mathrm{ng} / \mathrm{ml}$ at $60 \mathrm{~min}$ after feeding $(\mathrm{P}<0.05)$, whereas feeding of concentrate + hay in the 12-wk old group reduced the GH concentration. Plasma insulin concentration levels before feeding were significantly greater for the 12wk old group than for the 3 -wk old group $(\mathrm{P}<0.05)$. Feeding caused a significant increase in insulin concentrations in the 3 -wk old group from 4.1 to $34.1 \mu \mathrm{U} / \mathrm{ml}$ at 75 min after feeding $(\mathrm{P}<0.001)$, whereas it did not cause a significant increase in 12-wk old group. The pre-feeding glucose level was significantly greater for the 12-wk old group than for the 3-wk old group, and feeding caused a significant increase only in the 3 -wk old group $(\mathrm{P}<0.05)$.

The GH level in the animals maintained on a milk replacer diet until $12 \mathrm{wk}$ of age slightly increased after feeding, but was not significantly different from that of the age-matched weaned animals. However, postprandial insulin levels of the group maintained on a milk replacer diet drastically and significantly increased to $221.1 \mu \mathrm{U} / \mathrm{ml}(\mathrm{P}<0.001)$. The glucose level significantly increased after feeding, which was significantly greater than that of the control $(\mathrm{P}<0.05)$. Plasma concentrations of IGF-I were significantly greater in the group maintained on a milk replacer diet than in the control group $(\mathrm{P}<0.01)$.

The GHRH or GHRP-6 injection significantly increased the GH level in both groups $(\mathrm{P}<0.05)$. The $\mathrm{GH}$ secretion for the 3 -wk old animals was greater than 
that for 12-wk old animals in both cases $(\mathrm{P}<0.05)$. However, GHRP-6, but not GHRH, injection significantly increased the insulin level for the 12-wk old group $(\mathrm{P}<0.05)$. Plasma glucose concentration was not significantly changed by the injection.

\section{DISCUSSION}

Plasma GH concentrations in 3-wk (pre-weaning) calves were different from those in 12-wk old (post-weaning) calves, although previous reports on the postprandial plasma GH levels were conflicting (see Katoh and Obara, 2001). The mechanism underlying the difference in post-prandial GH levels between pre- and post-weaning animals remains to be clarified. We postulated the physiological role of short-chain fatty acids produced by microbes in the forestomachs (the reticulorumen) which are involved in the inhibitory mechanism for the postprandially reduced GH levels (Katoh and Obara, 2001).

The postprandial and agonist-induced GH increases shown in preweaning animals seem to be dependent on age-associated processes. These results suggest that although bovine somatotrophs differentiate and possess GHRH receptors and relevant intracellular signaling system at an early state of gestation (Katoh and Obara, 2001), GH and insulin secretion around weaning in the calf, GH secretion in response to GHRH stimulation declines with the aging process in this species.

\section{CONCLUSIONS}

Feeding milk to 3 -wk old calves causes a significant increase in plasma concentrations of $\mathrm{GH}$, insulin and glucose, whereas feeding of concentrate + hay to 12-wk old animals does not. However, feeding-induced GH secretion in the animals maintained on a milk replacer diet until $12 \mathrm{wk}$ of age was not different from that in the age-matched weaned group. The difference in postprandial responses may be explained by the effect of aging, the quality of the diets or altered neuroendocrine functions in the digestive-pituitary system.

\section{REFERENCES}

Blum J.W., Hammon H., 1999. Endocrine and metabolic aspects in milk-fed calves. Domest. Anim. Endocrinol. 17, 219-230

Ishiwata H., Nagano M., Sasaki Y., Chen C., Katoh K., 2000. Short-chain fatty acids inhibit the release and content of growth hormone in goat anterior pituitary cells. Gen. Comp. Endocrinol. $118,400-406$

Katoh K., Obara Y., 2001. Developmental and nutritional control of the somatotropic axis in the ruminant. Asian-Austr. J. Anim. 14, Special Issue, 91-99 
Kitade K., Takahashi K., Yonekura S., Katsumata N., Furukawa G., Osuga S., Nishita T., Katoh K., Obara Y., 2002. Effects of nutritional conditions around weaning on carbonic anhydrase activity of the parotid gland and ruminal and abomasal epithelia of Holstein calves. J. Comp. Physiol. B 172, 379-385

Yonekura S., Kitade K., Furukawa G., Takahashi K., Katsumata N., Katoh K., Obara Y., 2002. Effects of aging and weaning on mRNA expression of leptin and CCK receptors in the calf rumen and abomasum. Domest. Anim. Endocrinol. 22, 25-35 